\title{
Electroosmotic Sampling. Application to Determination of Ectopeptidase Activity in Organotypic Hippocampal Slice Cultures
}

\author{
Hongjuan Xu†, Yifat Guy ${ }^{\dagger}$, Amy Hamsher ${ }^{\dagger}$, Guoyue Shi ${ }^{\dagger}$, Mats Sandberg ${ }^{\ddagger}$, and Stephen G. \\ Weber ${ }^{\dagger},{ }^{*}$ \\ † Department of Chemistry, University of Pittsburgh, 219 Parkman Avenue, Pittsburgh, \\ Pennsylvania 15260 \\ ‡ Institute of Biomedicine, Gothenburg University, Gothenburg, Sweden
}

\begin{abstract}
We hypothesize that peptide-containing solutions pulled through tissue should reveal the presence and activity of peptidases in the tissue. Using the natural $\zeta$-potential in the organotypic hippocampal slice culture (OHSC), physiological fluids can be pulled through the tissue with an electric field. The hydrolysis of the peptides present in the fluid drawn through the tissue can be determined using capillary HPLC with electrochemical detection of the biuret complexes of the peptides following a postcolumn reaction. We have characterized this new sampling method by measuring the flow rate, examining the use of internal standards, and examining cell death caused by sampling. The sampling flow rate ranges from 60 to $150 \mathrm{~nL} / \mathrm{min}$ with a $150 \mu \mathrm{m}$ (ID) sampling capillary with an electric field (at the tip of the capillary) from 30 to $60 \mathrm{~V} / \mathrm{cm}$. Cell death can be negligible with controlled sampling conditions. Using this sampling approach, we have electroosmotically pulled Leu-enkephalin through OHSCs to identify ectopeptidase activity in the $\mathrm{CA} 3$ region. These studies show that a bestatin-sensitive aminopeptidase may be critical for the hydrolysis of exogenous Leu-enkephalin, a neuropeptide present in the CA3 region of OHSCs.
\end{abstract}

Neuropeptides play a key role in brain and peripheral nervous system functions such as pain and learning ${ }^{1}$. They are mainly inactivated by ectopeptidases - outward-facing, membranebound peptidases that cleave the active peptides into inactive fragments ${ }^{2-4}$. Extracellular peptidases create active forms of $\mathrm{BDNF}^{5}$, substance $\mathrm{P}^{6}$, cholecystokinins ${ }^{4}$ and alter the activity of dynorphins ${ }^{7}$. Recent work shows that peptidases are important in the degradation of amyloid ${ }^{8,9}$. Also, attenuated peptidase activity following stroke can contribute to neurotoxicity and an endogenous blocker of the ectopeptidase that cleaves enkephalin has powerful analgesic effects ${ }^{10}$. Thus, a deeper understanding of peptidase activity is necessary for understanding both normal and pathological brain function, as well as for the development of novel strategies for drug development.

While the central focus of this paper is electroosmotic sampling, the determination of peptidase activity in tissue is an important direction. Peptidase activity has been a concern in microdialysis experiments. Microdialysis sampling of peptides is improved in the presence of peptidase inhibitors ${ }^{11-17}$. Recently, the Stenken group ${ }^{18,19}$ has developed microdialysis approaches to in vitro (enzyme solutions) determination of protease activity. In vitro (slice)

*Corresponding author: (tel) +1(412)624-8520; (fax) +1(412)624-1668; sweber@ pitt.edu.

SUPPORTING INFORMATION AVAILABLE

This material is available free of charge via the internet at http://pubs.acs.org. 
studies of peptidase inhibitors lead to knowledge of the peptidases active in a whole slice ${ }^{15}$, 20 . Finally, several research groups have analyzed peptidase activity (dynorphin $\mathrm{A}^{21,22}$, substance $\mathrm{P}^{23}, \beta$-endorphin ${ }^{24}$, and peptide $\mathrm{E}^{25}$ ) in vivo with microdialysis. Most of our understanding of peptidases has come from analysis of tissue extracts, homogenate or fraction by determination of peptide fragments by HPLC 26,27 or by standard enzyme methods (fluorogenic substrate) ${ }^{28,29}$. More modern methods are demonstrating more chemically detailed information at the organism level. For example, high resolution separations followed by mass spectrometry have been used to investigate a knockout mouse missing the gene producing dipeptidyl peptidase 4 allowing the discovery of the influence of that enzyme on the peptidome ${ }^{30,31}$. In another example, mass spectrometry was applied to the analysis of the differential peptidome in rat striatum resulting from $\mathrm{K}^{+}$-induced depolarization $^{32}$. The approaches illustrated open the possibility of asking and answering more refined questions about peptides and peptidases, including localized measurements in tissue, in vivo and in vitro. One pragmatic issue concerning analysis of ectopeptidase activity is that any tissue fractionation will release intracellular peptidases that will contribute to peptide breakdown. It follows that it is preferable to perform analysis of ectopeptidase activity with intact cells or tissues when possible.

The organotypic culture method provides a route to in vitro models of in vivo tissue. Stoppini and co-workers described a simple preparation technique for hippocampal organotypic cultures ${ }^{33}$. The hippocampus is a brain area responsible for some forms of memory and learning, and is highly susceptible to damage from seizures, ischemia and anoxia $^{34}$. Cultured hippocampal tissue survives for several weeks. The local synaptic circuitries are still functional and the structure of the hippocampus is well preserved ${ }^{35}$. In a wide spectrum of studies, the organotypic hippocampal slice culture (OHSC) has been established as a reliable model ${ }^{2}, 36$. For our purposes, OHSC-based assays allow for better control of the extracellular environment than is possible in vivo. Thus, for studying ectopeptidases, a medium free of soluble peptidases can be used ${ }^{3}$. Neuropeptide hydrolysis in the extracellular space in slice cultures has been reported ${ }^{37}$ using the classical sampling approach in which tissue is incubated in a solution containing substrate, and products are detected in the medium after some time. Although this gives a measure of the endopeptidase activity in the entire slice, ectoenzyme activity in subregions of a specific brain area such as the hippocampus is not possible with this approach.

We propose a novel sampling method based on electroosmosis and apply it to OHSCs. The $\zeta$-potential of OHSCs has been measured in our laboratory ${ }^{38}$. The $\zeta$-potential is the potential of an object along a shear plane that separates fixed charges on the object and a moving electrolyte solution adjacent to it. In the OHSC, the fixed charges originate from charges on cells and the extracellular matrix. Application of an electric field to a porous medium like the OHSC with fixed charges creates an electroosmotic (EO) flow of the electrolyte. EO flow is the bulk fluid flow derived from the force of the electric field on mobile counterions that reside near the fixed charges. The magnitude of EO flow depends linearly and independently on the magnitudes of $\zeta$-potential and the externally applied electric field. The OHSC's $\zeta$-potential is $-20--25 \mathrm{mV}$ suggesting that when an electric field is applied to the tissue, an electroosmotic flow containing extracellular solutes will be generated in the extracellular space. In this work, we demonstrate the feasibility of this novel electroosmotic sampling approach for extracelluar fluid extraction. We have applied this method to the determination of ectopeptidase activity on Leu-enkephalin in the CA3 region of rat OHSCs with HPLC-EC. 


\section{EXPERIMENTAL SECTION}

\section{Solutions}

All chemicals used in the preparation of OHSCs were purchased from Sigma (St. Louis, MO). All aqueous solutions were prepared with purified water from a Millipore Synthesis A10 system (Millipore Corporation, Billerica, MA). Gey's balance salt solution (GBSS) was fortified with $2.7 \mathrm{mM} \mathrm{MgSO}_{4}$ and $0.45 \% \mathrm{D}$-(+)-glucose. Culture medium consisted of 50\% basal medium Eagle, 25\% Earle's balanced salt solution, $23 \%$ horse serum, $25 \mathrm{U} / \mathrm{mL}$ penicillin streptomycin solution, $1 \mathrm{mM} \mathrm{L}$-glutamine and $7.5 \mathrm{~g} / \mathrm{L} \mathrm{D}$-(+)-glucose. Hepes buffered salt solution (HBSS) was composed of (mM): $143.4 \mathrm{NaCl}$, 5.0 HEPES, 5.4 KCl, 1.2 $\mathrm{MgSO}_{4}, 1.2 \mathrm{NaH}_{2} \mathrm{PO}_{4}, 2.0 \mathrm{CaCl}_{2}$, and $10 \mathrm{D}$-(+)-glucose. The $\mathrm{pH}$ was adjusted to 7.40 with $0.5 \mathrm{M} \mathrm{NaOH}$ before filtering $(0.45 \mu \mathrm{m}$ PTFE). HBSS was kept frozen until use.

Peptides, inhibitors and sources were as follows: YGGFL, GGFL, GGFM and thiorphan (Bachem Americas, Inc, Torrance, CA); 2-Guanidinoethylthio succinic acid (GEMSA), puromycin, captopril and bestatin (Sigma, St. Louis, MO); ${ }^{\mathrm{D}} \mathrm{Y}^{\mathrm{D}} \mathrm{AG} \mathrm{G}^{\mathrm{D}} \mathrm{F}_{\mathrm{L}}$ was synthesized by Biomedical Research Support Facilities (BRSF) of University of Pittsburgh. All solutions were prepared in HBSS solution.

\section{Preparation of OHSCs}

The procedures described here have been approved by the IACUC of the University of Pittsburgh. The preparation of OHSCs is slightly modified from the Stoppini culturing method ${ }^{33}$. After rats ( 7 days postnatal) were decapitated, the hippocampal area was removed and chopped into $400 \mu \mathrm{m}$ slices by a McIIwain tissue chopper (The Mickle Laboratory Engineering Co. Ltd, UK). Slices were placed in ice-cold GBSS solution using a dissecting microscope (Fisher Scientific, Pittsburgh, PA), the individual slices were then transferred onto membrane inserts $(0.4 \mu \mathrm{m}$-pore size culture plate insert, Millipore Corporation, Billerica, MA) in a 6-well plate (Millipore Corporation, Billerica, MA), The slices were cultured over culture medium in a humidified incubator (Thermo Electron Corporation, Asheville, $\mathrm{NC}$ ) at $37^{\circ} \mathrm{C}$ with $5 \% \mathrm{CO}_{2} /$ air. Medium was exchanged every three days. Slices were normally cultured for 6 to 8 days. Before use, medium was removed from the dishes and replaced with GBSS (refrigerated till use and warm up to $37^{\circ} \mathrm{C}$ ), incubated $\left(37^{\circ} \mathrm{C}\right)$ for 30 minutes, the previous step was repeated, and then the OHSCs were kept in $\operatorname{HBSS}\left(37^{\circ} \mathrm{C}\right)$.

\section{Cell Death Determination}

An inverted fluorescent microscope (Olympus IX71) with an Olympus Plan Apo 1.25x objective lens (both from Olympus, Melville, NY) was employed to image the OHSCs using a CCD camera (ORCA-285 IEEE 1394 -Based Digital Camera, Hamamatsu Photonics K.K., Japan). A Semrock (Rochester, NY) DA/Fl/TA-3X-A Triple-band "Pinkel" filter set (exciter I, $387 \mathrm{~nm}$; exciter II, $494 \mathrm{~nm}$; exciter III, $575 \mathrm{~nm}$; dichromatic mirror: 394-414 nm, 484$504 \mathrm{~nm}, 566-586 \mathrm{~nm}$; emitter: 457, 530, $628 \mathrm{~nm}$ ) was used for imaging of propidium iodide (PI)-stained OHSCs. Details of this procedure can be found in the companion paper ${ }^{39}$. Briefly, following a sampling experiment, OHSCs were provided with fresh medium containing PI (final concentration is about $12 \mu \mathrm{M}$ ). After 16 to 24 hours, images were taken for $\%$ death measurement. The $\%$ death measurement is based on the fluorescence intensity of the PI in the sampled area. One hundred\% death represents PI fluorescence from an OHSC killed by exposure to liquid methanol until opaque; $0 \%$ control OHSCs were handled (medium exchange, moved from incubator to lab and back) as experimental OHSCs, but were not sampled (Equation 1). 
where $M I$ represents mean fluorescence intensity of PI, $s$ is the sampled OHSC, $c$ is the $0 \%$ control OHSC, and $k$ is the $100 \%$ dead OHSC.

\section{Electroosmotic Sampling Set-up}

In the sampling set-up as displayed in Figure 1, we had: a) two Petri dishes containing the same volume of solution to avoid siphoning; b) an insert membrane to hold the OHSC; c) a sampling capillary with one tip positioned near the tissue surface and the other one dipped into buffer solution in the other dish; and d) two Pt electrodes connected to a power supply to complete the electric circuit. An electronic micromanipulator (Model TSX-1, Sutter Instrument Company, Novato, CA) was used to position the capillary tip. Once an electric field is applied, fluid is drawn into the sampling capillary by electroosmotic flow. Samples were ejected from the capillary using a $50 \mu \mathrm{L}$ syringe containing $40 \mu \mathrm{L}$ (sometimes $20 \mu \mathrm{L}$ ) $0.1 \%$ TFA. This represents approximately a 100 (50)-fold dilution. A further $2-37.5$-fold dilution depending on the concentration of peptide in the bath was made before injection into an HPLC-EC system for analysis. A $150 \mu \mathrm{m}$ ID $\times 30 \mathrm{~cm}$ (length) capillary was used in all experiments unless described otherwise.

\section{HPLC-EC System}

We utilized a Waters 600 E quaternary pump (Waters Corporation, MA) to deliver the mobile phase (23\% acetonitrile, 3\% 1-propanol, $0.1 \%$ trifluoroacetic acid and Milli-Q water) at $100 \mu \mathrm{L} / \mathrm{min}$ and a simple tee to split the flow. After splitting, the mobile phase flowed through a VICI injector (Valco Instruments Co., Houston, TX) and then a $75 \mu \mathrm{m}$ ID capillary column at about $1 \mu \mathrm{L} / \mathrm{min}$. The 9-cm long column was packed with $2.6 \mu \mathrm{m} \mathrm{C}_{18}$ particles in the laboratory as described by Kennedy et $\mathrm{al}^{40}$. Peptides were detected electrochemically following a postcolumn reaction. The effluent from the column was mixed with biuret reagent $(0.24 \mathrm{M}$ carbonate buffer, $12.0 \mathrm{mM}$ disodium tartrate and $2.0 \mathrm{mM}$ copper sulfate, $\mathrm{pH}$ 9.83) to form electrochemically active complexes which were detected at a $10 \mu \mathrm{m}$ carbon fiber electrode at an applied potential of $+0.55 \mathrm{~V}$ versus $\mathrm{Ag} / \mathrm{AgCl}$. Potential was controlled with a BAS Epsilon potentiostat (W. Lafayette, IN). Biuret reagent was delivered by an Isco model DM syringe pump (Harvard Apparatus, Holliston, MA) at $0.3 \mu 1 /$ $\min$. The post column derivatization was performed in a Capillary Taylor Reactor (CTR $)^{41}$ with an inner diameter of $75 \mu \mathrm{m}$. The HPLC-EC system was depicted by Xu et al. ${ }^{42}$. Under the specified conditions and with peptide concentrations less than $1 \mu \mathrm{M}$, this system gives baseline resolution for the peaks of interest. Peak height and peak area (PeakFit Version 4, AISN Software, Inc.) are proportional to concentration. Because we pack columns locally and we use flow splitting, there is a variability of retention times. Thus, peptide standards are always used for peak assignments.

\section{Observation of Electroosmotic Flow in Tissue}

This experiment was carried out to create an image that would demonstrate the phenomenon - that the application of an electric field pulls solution through the tissue. Samples obtained from this experiment were not analyzed. An insert membrane supporting an OHSC was placed into a Petri dish $(60 \times 15 \mathrm{~mm})$ containing approximately $3 \mathrm{~mL}$ of HBSS. A100 $\mu \mathrm{m}$ ID $\times 30 \mathrm{~cm}$ long fused-silica sampling capillary filled with HBSS was held orthogonal to and just touching the OHSC. The proximal end of the capillary was placed in a vial containing HBSS and a platinum wire (1 $\mathrm{mm}$ diameter). The vial was sealed and positioned to avoid siphoning. A gold minigrid electrode $(\sim 5 \mu \mathrm{m}$ thick) was placed on the bottom of the Petri dish, under the insert membrane/OHSC. The platinum wire and gold minigrid were 
connected to a high voltage power supply (Stanford Research Systems, model PS350, Sunnyvale, CA). A slit was cut into the side of the Petri dish, allowing for a $25 \mu \mathrm{m}$ ID fusedsilica injection capillary to be positioned under the insert membrane and above the gold minigrid. Capillaries were cut flat and clean using a Shortix capillary cutter with a diamond blade (Middelburg, Netherlands). The injection capillary was filled with $10 \mu \mathrm{M}$ Thioglo-1 (Covalent Associates, St. Louis, MO) in HBSS. The tissue and minigrid were in the optical path of the IX-71 inverted fluorescence microscope and imaged using a U Plan Apo 4x objective lens (Olympus) and a specially-built Omega fluorescence cube (Omega, Brattleboro, VT): $378 \mathrm{~nm}$ excitation and $480 \mathrm{~nm}$ emission. Simple PCI software acquired the images. When the tissue is in place, image acquisition was initiated. In experiments (controls) three (zero) $\mathrm{kV}$ were applied to the system, followed by the injection of Thioglo-1 dye under the insert membrane.

\section{RESULTS AND DISCUSSION}

\section{Demonstration of Electroosmotic Sampling}

a. Proof of Principle-Initial proof of principle experiments were carried out by exposing tissue to a low concentration of a neutral, membrane permeant, thiol reactive, fluorogenic reagent, Thioglo-1. This reagent reacts with thiols in the cell, chiefly glutathione (GSH). Cells exposed to this reagent become fluorescent rapidly. In experiments, a blunt-ended, electrolyte-filled capillary was placed on the tissue. Contact with the tissue can be discerned while doing the capillary placement, however the image of the end of the capillary when it is in place is quite variable, as the image is taken through the minigrid, the support membrane, and the tissue. (See Figure 2: A1 and B1). A brief injection of the Thioglo-1-containing electrolyte under the insert membrane supporting the tissue leads to significant fluorescence under the capillary and in the capillary lumen in the experiment (B1-B3 in Figure 2). In the control where no electric field is applied, no change is observed in the image (A1-A3 in Figure 2). This demonstrates that application of an electric field through the OHSC and insert membrane into a fused-silica capillary creates an electroosmotic flow into the capillary lumen. Thus, the cells around the capillary opening fluoresce with Thioglo-1. Without the electric field, there is no change in the luminescence intensity near the sampling capillary.

b. Peptide Sampling-YGGFL is a neutral neuroactive peptide. Its enzymatic hydrolysis was employed as a probe to evaluate electroosmotic sampling. We used ${ }^{D} Y^{D} A G^{D}{ }^{D} L$, an analog of YGGFL containing D amino acids, as an internal standard (IS). This peptide is resistant to enzymatic degradation ${ }^{43}$. Solutions of the IS and YGGFL in HBSS comprise the medium during sampling. As described in the experimental section, an electrolyte-filled capillary is placed perpendicular to and near or touching the surface of an OHSC which is in contact with the medium through an insert membrane. When current flows from the medium beneath the OHSC into the capillary, electroosmotic flow will carry neutral molecules of similar size and shape into the capillary at about the same flow rate. Thus YGGFL and the IS will have very similar velocities since they are both virtually neutral and they have similar molecular weights. The biuret complex of the IS also has a similar electrochemical response to the biuret complex of YGGFL. Thus, if the concentrations of the two species are the same in the bath, the YGGFL peak will have a similar area to the IS peak if there is no enzymatic degradation.

Figure 3 displays typical chromatograms of the samples obtained by electroosmotic sampling. GGFL elutes first, followed by YGGFL and then IS. When samples are drawn through the OHSC, some of YGGFL is hydrolyzed into GGFL. The sum of the YGGFL and GGFL concentration is still smaller than that of the IS, implying the presence of other 
undetectable products. When the capillary tip was moved onto the insert membrane surface adjacent to the slice culture, the YGGFL peak is almost as large as the IS peak which means most of YGGFL remains intact during the sampling. Only a small GGFL peak is observed. The small GGFL peak results from the presence of cells in the membrane adjacent to the culture itself. The results clearly indicate that YGGFL has been carried through the slice culture and that it was hydrolyzed in the tissue. The result verifies the feasibility of this novel electroosmotic sampling method and implies its possible application in the enzymatic studies.

Damage caused by electroosmotic sampling: Figure 4 contains representative images of slice cultures taken before and after electroosmotic sampling compared with the image of a slice culture exposed to methanol. When the electrolyte-filled capillary tip was positioned directly on the surface of the slice culture, some cell death appears around the sampling area 18-24 $\mathrm{h}$ after sampling (a red area shows up in A2 compared with A1, the image taken from the same slice culture before electroosmotic sampling) but the rest of slice looks normal. When the capillary tip was placed $50 \mu \mathrm{m}$ away from the surface of the slice culture (with electrolyte connecting them), no obvious damage occurs (no darker red is observed in B2 compared with B1). We report in more detail in a companion paper $^{39}$ that $\%$ death is less than $10 \%$ when sampling in CA3 for $5 \mathrm{~min}$ at an electric field of $46.7 \mathrm{~V} / \mathrm{cm}$, with a capillary having an inner diameter less than or equal to $180 \mu \mathrm{m}$, and positioned $15 \mu \mathrm{m}$ or more from the surface.

The investigation of ectopeptidase activity should be immune to misinterpretation from damage. As membrane-bound proteins, their volume-average concentration does not change on the minutes timescale over which sampling occurs. They do not rely on metabolism to function. Indeed, most assays begin by homogenizing the tissue! Thus, our approach is quite gentle by comparison. This is not to say that the cell death and even the electric field itself may be unwanted in a particular experiment. Certainly, a level of caution must be used in applying any sampling procedure to live tissue.

The $\zeta$-potential of a OHSC has been measured to be about $-22 \mathrm{mV}$ in our laboratory ${ }^{38}$, while it is about $-50 \mathrm{mV}$ for a silica capillary after proper preconditioning. The mismatch in $\zeta$-potential produces a pressure driven flow into the capillary which forces the slice surface against the capillary tip during electroosmotic sampling. This may contribute to the physical damage when the capillary is actually touching the tissue. Joule heating at the capillary tip might be another source of the damage.

To see whether the sampling process causes the release of cytosolic enzymes during electoosmotic sampling, we carried out the following experiments under conditions as given in Figure 4: samples were collected and split after sampling. One aliquot was mixed with $0.1 \%$ TFA (to stop enzyme activity) right after the sample was collected, whereas the other aliquot remained at room temperature for $45 \mathrm{~min}$ before $0.1 \%$ TFA was added. The conversion rates of GGFL from YGGFL, defined as $[G G F L] /([G G F L]+[Y G G F L])$, were measured for both aliquots. The differences in conversion rates (shown in Table 1) were statistically zero (four repeats; $\%$ difference ranging from $-5 \%$ to $2 \%, p=0.38$ for null hypothesis that there is no difference). Thus, YGGFL hydrolysis did not continue after the sample collection implying that no soluble cytosolic peptidases were extracted. Therefore, only the membrane-bound ectopeptidases hydrolyze YGGFL during electroosmotic sampling. This is an advantage in comparison to procedures that homogenize tissue. Sampling the extracellular space excludes the influence from those membrane-bound enzymes having their active sites facing intracellularly. 


\section{Measurement of Sampling Flow Rate}

a. Single IS Method-During electroosmotic sampling, existing extracellular fluid reaches the sampling capillary before solution from the bath that is drawn through the OHSC. It is the latter solution that contains IS. Thus, the total sampled volume should be the sum of these two volumes as expressed below:

$$
V_{S}=V_{E C F}+V_{B A T H}
$$

$V_{E C F}$ and $V_{B A T H}$ represent the sampled volume from the extracellular space and the bath solution, respectively. $V_{B A T H}$ is obtained from sampled $\mathrm{mol}_{I S}$ (see equation 2 in Supporting Information) divided by the initial concentration of IS in the bath. $V_{S}$, the total sampled volume, is proportional to the applied electric field. By rearranging Eq. 2, we obtained

$$
V_{B A T H}=V_{S}-V_{E C F}=k E t-V_{E C F}
$$

$E$ is the applied electric field, $t$ is the sampling time, and $k$ is related to the 'apparent' $\zeta$ potential $\left(\zeta_{\mathrm{APP}}\right)$ in the tissue by

$$
k=-\left(\varepsilon \zeta_{A P P} / \eta\right) \pi \cdot a^{2}
$$

where $a$ is capillary radius, $\varepsilon$ is permittivity, and $\eta$ is viscosity. We use 'apparent' $\zeta$-potential to account for the $\zeta$-potential mismatch between the capillary and the OHSC mentioned above. There will be a small contribution from pressure-induced flow adding to the electroosmotic flow. As we do not explicitly account for this in Eq. 4, we use an apparent $\zeta$ potential. By plotting $V_{B A T H}$ against $E$, we obtained $V_{E C F}$ from the y intercept as $205 \pm 55$ $\mathrm{nL}$. The sampling flow rate can be calculated as $V_{S}$ divided by the sampling time. It ranges from 60 to $150 \mathrm{~nL} / \mathrm{min}$ under the conditions applied. The apparent $\zeta$-potential is about -29 $\mathrm{mV}$ slightly larger in magnitude than the measured $\zeta$-potential of an OHSC, $-22 \pm 2 \mathrm{mV}$. The observed difference between the previously measured and the apparent $\zeta$-potentials is consistent with the flow having a small pressure-induced component due to the larger (negative) $\zeta$-potential in the capillary.

It is interesting to note that the applied field controls where the sample comes from. The linear regression of $V_{B A T H}$ on $E\left(V_{B A T H}=10.3 E(\mathrm{~V} / \mathrm{cm})-205 \mathrm{~nL}\right)$ shows that a field of 20 $\mathrm{V} / \mathrm{cm}$ will provide a $V_{B A T H}$ of zero. Thus, fields below $20 \mathrm{~V} / \mathrm{cm}$ provide extracellular fluid from the tissue under the conditions used, whereas fields greater than that will sample fluid from the bath below as well as the extracellular fluid. Consequently, conditions for obtaining the extracellular fluid, and thus capturing endogenous species, are easily attained.

b. Two IS Method-In many experiments, an average flow rate based on the data just discussed may be sufficient. However, it would be beneficial in some circumstances to have an indication of the flow rate for each run. GGFM, used as a second internal standard, is filled in the sampling capillary. When sampling starts, GGFM solution is gradually replaced by extracellular fluid and then by bath solution. Thus, the sampling capillary is filled with GGFM solution, extracellular fluid and bath solution in the end if the sampling time is not too long. Eq. 5 expressed the volume distribution in the capillary. 


$$
V_{\text {capillary }}=V_{G G F M}+V_{E C F}+V_{B A T H}=V_{G G F M}+V_{S}
$$

In every run of sampling, both $V_{G G F M}$ and $V_{B A T H}$ can be indirectly obtained from the chromatograms. $V_{\text {capillary }}$ is determined based on a chromatogram from the capillary filled with GGFM solution only. $V_{S}$ and $V_{E C F}$ can be calculated according to Eq. 5. Thus, the two IS method allows a direct determination of sampling flow rate in every run. The average sampling flow rate, $112 \pm 43$ (s.d.) $\mathrm{nL} / \mathrm{min}$ at an electric field of $50 \mathrm{~V} / \mathrm{cm}$, is indistinguishable from $103 \mathrm{~nL} / \mathrm{min}$, obtained from the single IS method under the same conditions. The large standard deviation confirms the need for this two IS method. The sampling flow rate is easily adjusted by the applied electric field and the diameter of the capillary.

Sampling Bias: The observed mobility of a molecule in the extracellular space is the sum of its electroosmotic mobility and its electrophoretic mobility. For a negatively charged species whose electrophoretic mobility opposes its electroosmotic mobility, sampling could be a problem. According to Eq.6,

$$
u_{O B S}=u_{C E}+u_{E O}=\frac{z}{6 \pi \eta r}+\frac{\varepsilon \zeta}{\eta}
$$

where $u_{O B S}, u_{C E}$ and $u_{E O}$ represent the observed mobility, electrophoretic mobility and electroosmotic mobility, respectively. $z$ is the net charge of the molecule, $\eta$ is viscosity, $r$ is the Stokes radius, $\varepsilon$ is permittivity and $\zeta$ is zeta potential. For a low-molecular-weight species with a negative charge of -0.6 , the solute's velocity is 0 as the electroosmotic and electrophoretic mobilities are equal and opposite. In practice, however, the pressure-driven flow generated by the $\zeta$-potential mismatch works to minimize this problem. For example, fluorescein which is practically a dianion at physiological $\mathrm{pH}$, can be sampled electroosmotically.

Indentifying the Peptidase Pharmacologically by Electroosmotic Sampling: There are several peptidases that may act upon Leu-enkephalin in rat brain. The aminopeptidases (aminopeptidase N (APN), puromycin-sensitive aminopeptidase (PSA) and two neuron specific aminopeptidases (NAP and NAP2)) cleave the N-terminal tyrosine from enkephalins. Other enzymes include carboxypeptidase, angiotensin-converting enzyme (ACE), dipeptidyl aminopeptidase (DAP) and enkephalinase (NEP), which hydrolyze YGGFL at other amide bonds. This aminopeptidases can be separated into two categories: bestatin-sensitive aminopeptidase (APN) and puromycin-sensitive aminopeptidase (PSA, NAP and NAP2). Puromycin-sensitive aminopeptidases are effectively inhibited at $20 \mu \mathrm{M}$ puromycin ${ }^{44-46}$. Carboxypeptidases cleave YGGFL at the Phe-Leu amide bond with a $K_{m}$ in the $\mathrm{mM}$ range ${ }^{47}$. This enzyme is specifically inhibited by GEMSA. DAP cleaves YGGFL into YG and GFL. This peptidase is primarily located in the cytosol -its membrane activity is low ${ }^{48}$. NEP and ACE cleave YGGFL to produce YGG and FL ${ }^{49}$. Thiorphan is a selective inhibitor for NEP while captopril inhibits ACE. Based on this information, we used puromycin, thiorphan, GEMSA, captopril, and bestatin to selectively block particular classes of peptidases in order to determine which peptidase is the most important in YGGFL hydrolysis in OHSCs. Typical chromatograms are displayed in Figure 5. Note that high concentrations of YGGFL were used because of the high $K_{m}$ values anticpated. An approximately $200-3700$-fold dilution of the sample preceded analysis to keep the injected concentration less than $1 \mu \mathrm{M}$ (see experimental section). 
GGFM elutes at about $10.5 \mathrm{~min}$, followed by GGFL, YGGFL and IS. Four experiments were performed under conditions described in Figure 5. A one-way analysis of variance of the enzyme rate based on either GGFL production or YGGFL loss (see SI for the derivation of enzyme rate) shows that a significant difference exists among experiments $\mathrm{A}, \mathrm{B}, \mathrm{C}$, and D. However, there is no significant difference among experiments A, B, and C. Thus, bestatin is the most effective inhibitor. We conclude that a bestatin-sensitive aminopeptidase may contribute in the inactivation of exogenous YGGFL in the extracellular space in the CA3 region of the hippocampus.

The degradation paths of YGGFL depend on the tissue being studied and the method of measuring enzyme activity. The cleavage of the Tyr-Gly amide bond represents the only detectable inactivation pathway in homogenates or soluble fractions of brain tissue, while cleavage of the Gly-Phe bond represents about $20 \%$ with particulate fractions ${ }^{50}$ and may even reach $65 \%$ with synaptosomes ${ }^{51}$. In our observations in the OHSC, $72 \%$ of YGGFL hydrolysis occurs at Tyr-Gly. The hydrolysis at Tyr-Gly of exogenous YGGFM in rat striatal slices is about $80 \%$ of the total hydrolysis ${ }^{37}$, which is similar to our result. In this experiment, YGGFM diffuses into the entire extracellular space and reacts with the ectoenzymes. There is a considerable variation in enkephalin-degrading activity across the human brain $^{52}$. This emphasizes the necessity of spatial resolution, something that the current approach can provide.

Finally, we challenged OHSCs with different concentrations of YGGFL to determine a value of $K_{m}$. The initial velocity is defined as [GGFL] $/ t_{e}$, where $t_{e}$ is the exposure time of YGGFL in the OHSC (see SI for details of $t_{e}$ derivation) $t_{e}$ is calculated to be $1.5 \mathrm{~s}$ under the conditions used. This calculation involves the assumption that the sampled volume is a cylinder in the tissue with the same diameter as the inside diameter of the sampling capillary, which is probably an underestimate. The initial velocity is plotted (Figure 6) as a function of [YGGFL], the initial concentration of the substrate. The YGGFL hydrolysis displayed a typical Michaelis-Menten behavior. We obtained $V_{\max }$ and $K_{m}$ as $770 \pm 95 \mu \mathrm{M} / \mathrm{s}$ and $1.2 \pm 0.5 \mathrm{mM}$, respectively. This $K_{m}$ value is similar to published values. While endogenous peptide concentrations tend to be low, peptidase $K_{m}$ values are rather high. The high $K_{m}$ values are consistent with the modest selectivity that is typical of peptidases.

Electroosmotic sampling appears to be effective. We have not determined the spatial resolution here quantitatively, however it is well known that the electric field, and thus electroosmotic velocity, decreases steeply as a function of distance from the tip. Of course, the electroosmotic velocity also depends on the applied field. We estimate, based on the images of tissue damage (when it occurs) that the spatial resolution is on the order of several hundred micrometers. This will need to be established more rigorously in the future. This distance dependence is proportional to the inside diameter of the capillary While there are complexities caused by the inhomogeneous electric field in the tissue, the overall approach is simple and ideally suited to slices or sampling from the surface of an organ, for example. In vivo application can be envisioned with narrower or pulled capillaries. Peptidase chemistry, e.g., selectivity, is very well understood (see http://merops.sanger.ac.uk/). However, ectopeptidase activity in intact tissue with spatial resolution is not. Imaging approaches based on fluorescence-generating substrates can provide more detailed information, even at the single-cell level, about the presence of peptidases ${ }^{53-55}$. For answering questions about native substrate metabolism, its space-and time-dependence, analysis of the native peptide substrate and its hydrolysis products is essential. The ability to measure peptidase activity with chemical and spatial selectivity should improve our understanding of how this important class of enzymes controls extracellular peptide activity. Electoosmotic sampling could find its application as well in extracellular endogenous peptide extraction and determination when combined with appropriate quantitative 
analytical approaches. An important question is the relationship between the extracellular concentration and the concentration in the sampled fluid. While this remains to be determined, we have good reason to believe that calibration in a suitable matrix, e.g., sampling from a well-characterized hydrogel with a known $\zeta$-potential, will be possible.

\section{Supplementary Material}

Refer to Web version on PubMed Central for supplementary material.

\section{Acknowledgments}

We thank Biomedical Research Support Facilities (BRSF) of University of Pittsburgh for peptide synthesis. This work is supported by grant R01 GM04482 from NIH.

\section{References}

1. Oegren SO, Kuteeva E, Elvander-Tottie E, Hoekfelt T. Eur J Pharmacol 2009;626:9-17. [PubMed: 19837050]

2. Kenny AJ. Peptidergic Neuron 1996:87-102.

3. Konkoy CS, Davis TP. Trends Pharmacol Sci 1996;17:288-294. [PubMed: 8810875]

4. Roques BP. Trends Pharmacol Sci 2000;21:475-483. [PubMed: 11121837]

5. Lee R, Kermani P, Teng KK, Hempstead BL. Science (Washington, DC, U S) 2001;294:1945-1948.

6. Karlsson K, Sharma H, Nyberg F. Biomed Chromatogr 2006;20:77-82. [PubMed: 15954166]

7. Taira A, Tanno K, Sakurada T, Tadano T, Kisara K. Annu Rep Tohoku Coll Pharm 1996;43:139145 .

8. Liu Y, Studzinski C, Beckett T, Guan H, Hersh MA, Murphy MP, Klein R, Hersh LB. Mol Ther 2009;17:1381-1386. [PubMed: 19471248]

9. Thevenet J, Angelillo-Scherrer A, Price M, Hirt L. J Neurochem 2009;111:828-836. [PubMed: 19719823]

10. Wisner A, Dufour E, Messaoudi M, Nejdi A, Marcel A, Ungeeheuer MN, Rougeot C. Proc Natl Acad Sci U S A 2006;103:17979-17984. [PubMed: 17101991]

11. Charli JL, Mendez M, Vargas MA, Cisneros M, Assai M, Joseph-Bravo P, Wilk S. Neuropeptides 1989;14:191-196. [PubMed: 2575716]

12. Kajiro T, Nakajima Y, Fukushima T, Imai K. Anal Chem 2002;74:4519-4525. [PubMed: 12236364]

13. Littlewood GM, Iversen LL, Turner AJ. Biochem Soc Trans 1987;15:894-895.

14. Mauborgne A, Bourgoin S, Benoliel JJ, Hirsch M, Berthier JL, Hamon M, Cesselin F. J Pharmacol Exp Ther 1987;243:674-680. [PubMed: 2445957]

15. Rose C, Vargas F, Silhouette B, Devaux B, Schwartz JC. Neuropeptides 1995;28:157-160. [PubMed: 7791959]

16. Williams JT, Christie MJ, North RA, Roques BP. J Pharmacol Exp Ther 1987;243:397-401. [PubMed: 3668866]

17. You ZB, Nylander I, Herrera-Marschitz M, O'Connor WT, Goiny M, Terenius L. Neuroscience (Oxford) 1994;63:415-425.

18. Steuerwald AJ, Villeneuve JD, Sun L, Stenken JA. J Pharm Biomed Anal 2006;40:1041-1047. [PubMed: 16242888]

19. Wang Y, Zagorevski DV, Stenken JA. Anal Chem 2008;80:2050-2057. [PubMed: 18278883]

20. Giros B, Gros C, Solhonne B, Schwartz JC. Mol Pharmacol 1986;29:281-287. [PubMed: 2869404]

21. Klintenberg R, Andren PE. J Mass Spectrom 2005;40:261-270. [PubMed: 15706626]

22. Reed B, Zhang Y, Chait BT, Kreek MJ. J Neurochem 2003;86:815-823. [PubMed: 12887680]

23. Freed AL, Cooper JD, Davies MI, Lunte SM. J Neurosci Methods 2001;109:23-29. [PubMed: 11489296] 
24. Reed B, Bidlack JM, Chait BT, Kreek MJ. J Neuroendocrinol 2008;20:606-616. [PubMed: 18363801]

25. Zhang H, Stoeckli M, Andren PE, Caprioli RM. J Mass Spectrom 1999;34:377-383. [PubMed: 10226364]

26. Ayyoub M, Monsarrat B, Mazarguil H, Gairin JE. Rapid Commun Mass Spectrom FIELD Full Journal Title:Rapid Communications in Mass Spectrometry 1998;12:557-564.

27. Muller S, Ho B, Gambus P, Millard W, Hochhaus G. J Pharm Biomed Anal 1997;16:101-109. [PubMed: 9447557]

28. Bell Hannah L, Gooz M. Am J Med Sci 339:105-107. [PubMed: 20087163]

29. Brama PAJ, TeKoppele JM, Beekman B, Van El B, Barneveld A, Van Weeren PR. Ann Rheum Dis 2000;59:155-157. [PubMed: 10666176]

30. Tagore DM, Nolte WM, Neveu JM, Rangel R, Guzman-Rojas L, Pasqualini R, Arap W, Lane WS, Saghatelian A. Nat Chem Biol 2009;5:23-25. [PubMed: 19011639]

31. Tinoco AD, Tagore DM, Saghatelian A. J Am Chem Soc 132:3819-3830. [PubMed: 20178363]

32. Haskins WE, Watson CJ, Cellar NA, Powell DH, Kennedy RT. Anal Chem 2004;76:5523-5533. [PubMed: 15362916]

33. Stoppini L, Buchs PA, Muller D. J Neurosci Methods 1991;37:173-182. [PubMed: 1715499]

34. Holopainen IE. Neurochem Res 2005;30:1521-1528. [PubMed: 16362771]

35. Cho S, Wood A, Bowlby MR. Curr Neuropharmacol 2007;5:19-33. [PubMed: 18615151]

36. Bausch SB. Neuromethods 2009;40:183-201.

37. De La Baume S, Yi CC, Schwartz JC, Chaillet P, Marcais-Collado H, Costentin J. Neuroscience 1983;8:143-151. [PubMed: 6300726]

38. Guy Y, Sandberg M, Weber SG. Biophys J 2008;94:4561-4569. [PubMed: 18263658]

39. Hamsher A, Xu HGY, Sandberg M, Weber Stephen G. submitted to Anal. Chem.

40. Kennedy RT, Jorgenson JW. Anal Chem 1989;61:1128-1135.

41. Beisler Amy T, Sahlin E, Schaefer Kathleen E, Weber Stephen G. Anal Chem 2004;76:639-645. [PubMed: 14750858]

42. Xu H, Weber SG. J Chromatogr, A 2009;1216:1346-1352. [PubMed: 19150071]

43. Wade D, Boman A, Waahlin B, Drain CM, Andreu D, Boman HG, Merrifield RB. Proc Natl Acad Sci U S A 1990;87:4761-4765. [PubMed: 1693777]

44. Gros C, Giros B, Schwartz JC. Biochemistry 1985;24:2179-2185. [PubMed: 2859885]

45. Hui KS, Saito M, Hui M. J Biol Chem 1998;273:31053-31060. [PubMed: 9813004]

46. Hui M, Hui KS. Neurochem Int 2008;53:317-324. [PubMed: 18831998]

47. Schwartz JC. Trends Neurosci 1983:15-18.

48. Horsthemke B, Hamprecht B, Bauer K. Biochem Biophys Res Commun 1983;115:423-429. [PubMed: 6626198]

49. Hersh LB. Mol Cell Biochem 1982;47:35-43. [PubMed: 6752692]

50. Schwartz JC, Malfroy B, De la Baume S. Life Sci 1981;29:1715-1740. [PubMed: 6272046]

51. Vogel Z, Altstein M. Endog. Exog. Opiate Agonists Antagonists. Proc Int Narc Res Club Conf 1980:353-356.

52. Mosnaim AD, Nguyen TD, Tse R, Puente J, Couceyro P, Wolf ME. Neurochem Res 2008;33:8186. [PubMed: 17676390]

53. Hobson JP, Liu S, Leppla SH, Bugge TH. Methods Mol Biol 2009;539:115-129. [PubMed: 19377967]

54. Linder KE. Application :44.

55. Rajopadhye, M.; Groves, K.; Preda, DV. Application. Visen Medical, Inc; USA: 2009. p. 121 


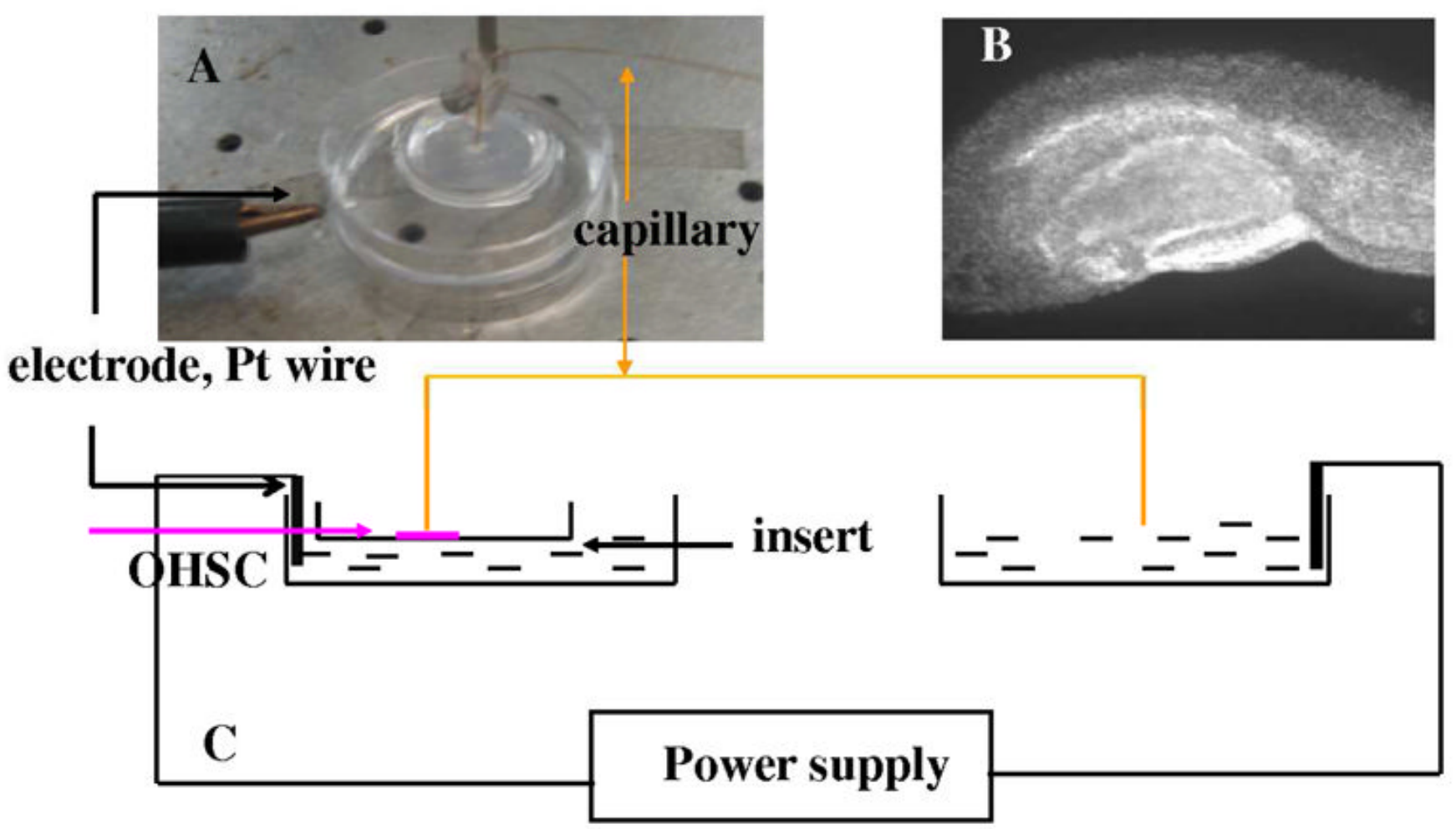

Figure 1.

The set-up for electroosmotic sampling. A. a picture of the left side of the set-up B. a bright field image of an OHSC C. a schematic figure of the set-up. 


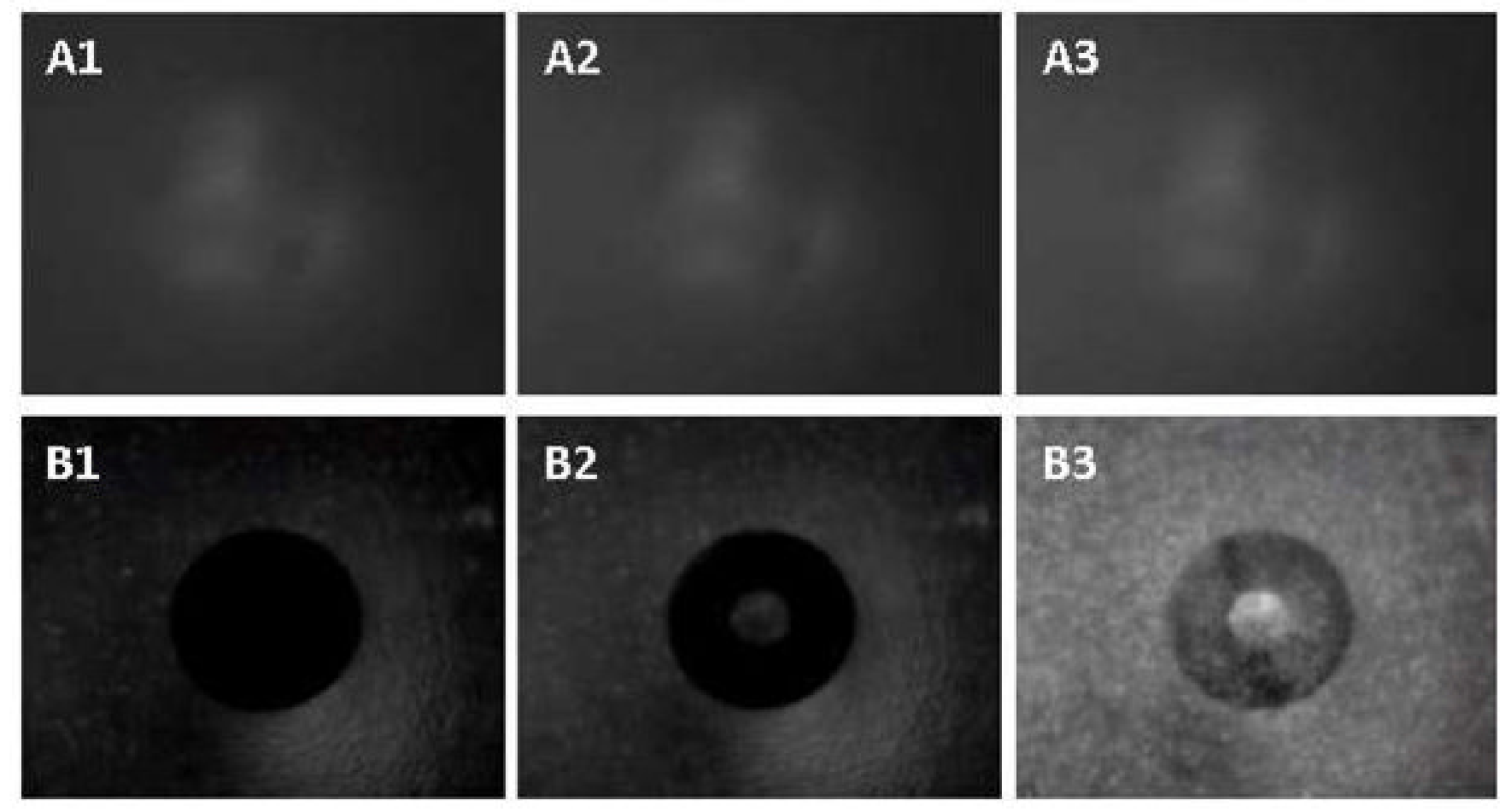

Figure 2.

Inverted fluorescence image ( $4 \times$ objective lens) of an OHSC, grown on an insert membrane, with a fused silica capillary positioned orthogonally, directly above the OHSC. A. No applied voltage at time 1) $0 \mathrm{~s}$, 2) $6.6 \mathrm{~s}$, and 3) $13.2 \mathrm{~s}$. B. $3 \mathrm{kV}$ applied, images taken at times 1) $0 \mathrm{~s}$, 2) $6.6 \mathrm{~s}$, and 3) $13.2 \mathrm{~s}$. The Thioglo- 1 injection capillary is outside of the field of view of these capillaries. 


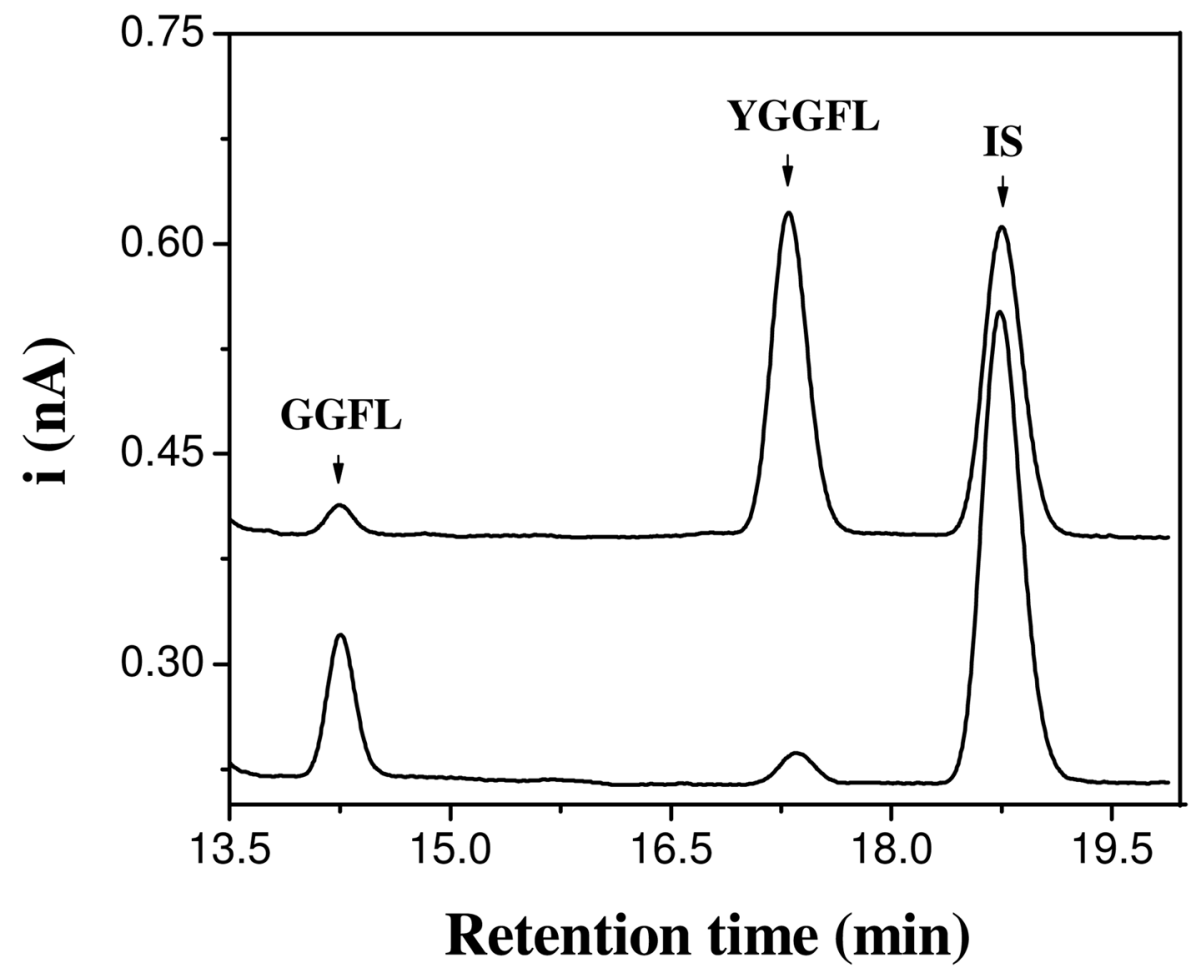

Figure 3.

Demonstration of electroosmotic sampling. Chromatograms of samples obtained by 5 min electroosmotic sampling at an electric field of $46.7 \mathrm{~V} / \mathrm{cm}$ with the capillary tip positioned on different surfaces: CA1 sub-region of an OHSC (top) and the surface of the same insert membrane adjacent to the OHSC (bottom). $150 \mu \mathrm{M}$ YGGFL and ${ }^{{ }^{D}} \mathrm{Y}^{\mathrm{D}} \mathrm{AG}^{\mathrm{D}} \mathrm{F}^{\mathrm{D}} \mathrm{L}$ (IS) in HBSS buffer solution served as the solution under the insert membrane. The samples were mixed with $20 \mu \mathrm{L} 0.1 \%$ TFA for the former case and $40 \mu \mathrm{L} 0.1 \%$ TFA for the latter. 

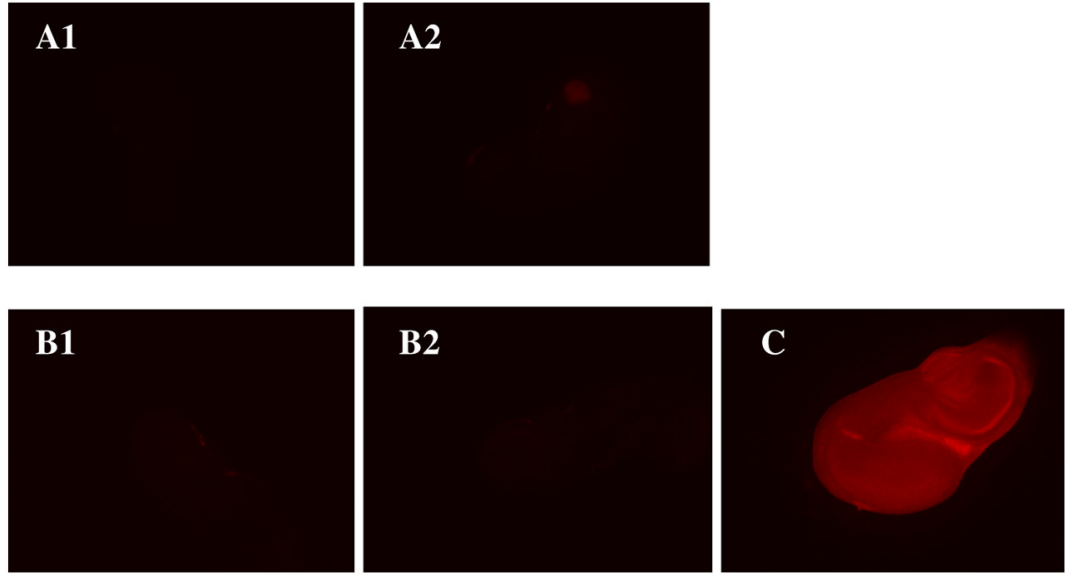

Figure 4.

Images of OHSCs before (A1, B1) and after (A2, B2) 5 min sampling at an electric field of $46.7 \mathrm{~V} / \mathrm{cm}$ with a $150 \mu \mathrm{m}(\mathrm{ID}) \times 30 \mathrm{~cm}$ capillary. The capillary tip was positioned directly on (A2) or $50 \mu \mathrm{m}$ away from theOHSC surface (B2). Image $\mathrm{C}$ is taken from a controlled OHSC treated with $\mathrm{MeOH}$. Image A1 and A2 were taken from the same OHSC, as were B1 and B2. 


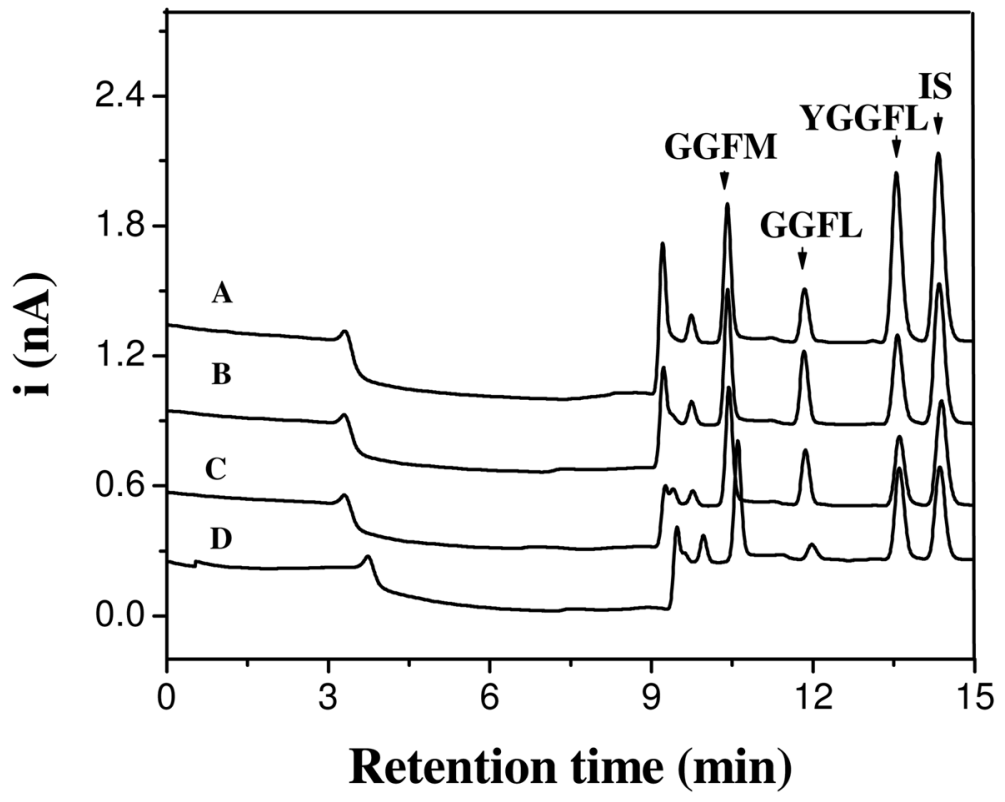

Figure 5.

5 min sampling through CA3 at $50 \mathrm{~V} / \mathrm{cm}$. The bath solution is HBSS with $150 \mu \mathrm{M}$ YGGFL and IS with or without inhibitors as follows: Experiment A, no inhibitors; B, includes inhibitors $(\mu \mathrm{M})$ of thiorphan (15), GEMSA (210), captopril (25). C, As B plus puromycin (20). D, as C plus bestatin (100). 


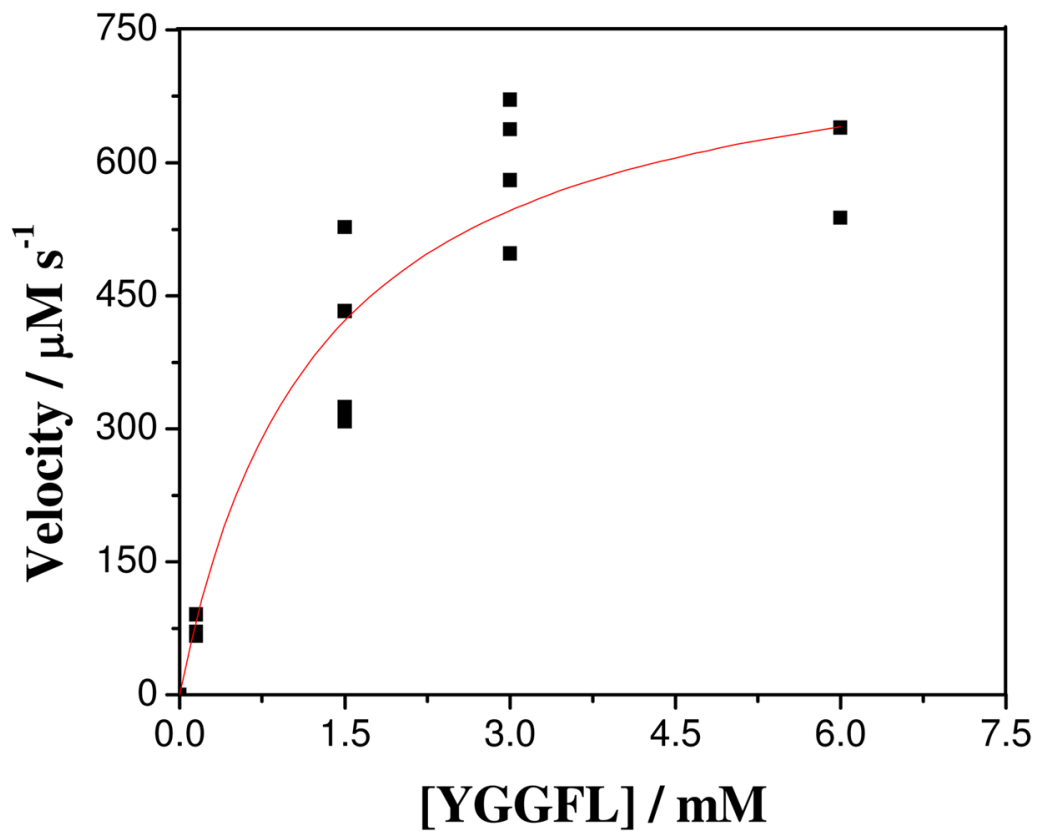

Figure 6.

Substrate saturation curve for ectoaminopeptidase-catalyzed YGGFL hydrolysis. All bath contains $15 \mu \mathrm{M}$ thiorphan, $210 \mu \mathrm{M}$ GEMSA, $25 \mu \mathrm{M}$ captopril and $20 \mu \mathrm{M}$ puromycin. 
Table 1

The Possibility of Cytosolic Enzyme Release under Very Tough Conditions

\begin{tabular}{ccccc}
\hline Runs & $\mathbf{1}$ & $\mathbf{2}$ & $\mathbf{3}$ & $\mathbf{4}$ \\
Difference in conversion rates & $-5 \%$ & $2 \%$ & $2 \%$ & $-1 \%$ \\
$p$-value of a student t-test & $=0.39$ & & \\
\hline
\end{tabular}

Electric field was $67.7 \mathrm{~V} / \mathrm{cm}$; capillary ID was $180 \mu \mathrm{m}$ and the sampling time was extended to be $15 \mathrm{~min}$. 